\title{
CONCEITO E PRÁTICA DO CONSENTIMENTO INFORMADO: UMA ANÁLISE DAS DECISÕES JUDICIAIS DO TRIBUNAL DE JUSTIÇA DO ESTADO DO RIO DE JANEIRO
}

\author{
CONCEPT AND PRACTICE OF INFORMED CONSENT: AN \\ ANALYSIS OF COURT DECISIONS OF THE RIO DE JANEIRO \\ STATE COURT OF JUSTICE
}

\section{CONCEPTO Y PRÁCTICA DEL CONSENTIMIENTO INFORMADO: UN ANÁLISIS DE LAS DECISIONES JUDICIALES DEL TRIBUNAL DE JUSTICIA DEL ESTADO DE RIO DE JANEIRO}

Dalmir Lopes Jr*

\begin{abstract}
1Introdução. 2 Conceito e elementos do Consentimento Informado. 2.1 Pré-condições: competência para a decisão e a voluntariedade. 2.1.1 Competência para decidir em questões de saúde. 2.1.2 Voluntariedade. 2.2 Elementos de informação. 2.3 Consentimento propriamente dito ou autorização para o ato médico. 3 Avanços e dificuldades do consentimento informado na prática judicial fluminense. 4 Conclusões. Referências.
\end{abstract}

\section{RESUMO}

O consentimento informado é um conceito resultante das transformações ocorridas na relação entre médicos e pacientes ao longo do século XX. A principal mudança deu-se com a superação do paradigma hipocrático de medicina por outro que privilegia o direito de autodeterminação dos pacientes. Embora ainda não exista uma lei que disponha sobre esse instituto no país, ele já é reconhecido pela jurisprudência pátria. A incorporação desse conceito pelo pensamento jurídico descortina uma nova compreensão para a relação médico-paciente. Neste artigo, procuramos discorrer sobre a natureza do consentimento informado, expondo seus requisitos e limites de aplicação. Para tanto, além de referenciais teóricos sobre a noção, também expomos uma pesquisa sobre a aplicabilidade do conceito a partir das decisões judiciais do Tribunal de Justiça do Estado do Rio de Janeiro entre os anos de 2002 a 2016, a fim de expor como a

Doutor em Bioética pelo Universidade Federal do Rio de Janeiro (UFRJ/PPGBIOS). Professor Adjunto do Departamento de Direito do Instituto de Ciências Humanas e Sociais da Universidade Federal Fluminense (UFF/VR) e do Programa de Pós-Graduação em Bioética, Ética Aplicada e Saúde Coletiva - PPGBIOS (programa em Associação UFRJ/FIOCRUZ/UERJ/UFF). Rio de Janeiro, Brasil. E-mail: <dalmirlopes@id.uff.br>. ORCID: https://orcid.org/0000-0002-2674-3748. 
prática judicial tem contribuído para a consolidação direito de autodeterminação do paciente, bem como quais são as dificuldades que ainda precisam ser superadas.

Palavras-chave: Consentimento informado. Autonomia. Relação médico-paciente. Tomada de decisão médica.

\begin{abstract}
Informed consent is a concept resulting from the transformations that occurred in the relationship between doctors and patients throughout the twentieth century. The main change occurred with the overcoming of the Hippocratic paradigm of medicine by another that privileges the patients' right of self-determination. Although there is not yet a law that provides for this institute in the country, it is already recognized by the case law. The incorporation of this concept by legal thought reveals a new understanding for the doctor-patient relationship. In this article we seek to discuss the nature of informed consent, exposing its requirements and application limits. For this, besides theoretical references about the notion, we also expose a research about the applicability of the concept from the court decisions of the State of Rio de Janeiro between 2002 and 2016, in order to expose how the process judice has contributed to the consolidation of the patient's right to self-determination, as well as the difficulties that still need to be overcome.
\end{abstract}

Keywords: Informed consent. Autonomy. Doctor-patient relationship. Medical decision making.

\title{
RESUMEN
}

El consentimiento informado es un concepto resultante de las transformaciones que ocurrieron en la relación entre médicos y pacientes a lo largo del siglo XX. El cambio principal ocurrió con la superación del paradigma hipocrático de la medicina por otro que privilegia el derecho de autodeterminación de los pacientes. Aunque todavía no existe una ley que establezca este instituto en el país, la jurisprudencia ya lo reconoce. La incorporación de este concepto por el pensamiento legal revela una nueva comprensión de la relación médico-paciente. En este artículo buscamos discutir la naturaleza del consentimiento informado, exponiendo sus requisitos y límites de aplicación. Para esto, además de las referencias teóricas sobre la noción, también exponemos una investigación sobre la aplicabilidad del concepto a partir de las decisiones judiciales del Tribunal de Justicia de lo Estado de Río de Janeiro entre 2002 y 2016, para exponer cómo el proceso judicial ha contribuido a la consolidación del derecho del paciente a la autodeterminación, así como las dificultades que aún deben superarse.

Palabras clave: Consentimiento informado. Autonomía. Relación médico-paciente. Toma de decisiones médicas. 


\section{INTRODUÇÃO}

É truísmo afirmar que, embora o objetivo do ato médico seja restabelecer a saúde do paciente, nem sempre ele é alcançado, quer porque o profissional, como qualquer ser humano, comete um erro, quer porque o tratamento realizado tem consequências que afetam substancialmente a qualidade de vida da pessoa. A obviedade de que goza essa afirmação não é a mesma que reside na pergunta: a quem cabe a palavra final sobre as decisões médicas? Ao profissional, detentor do conhecimento técnico, ou ao paciente, principal afetado pela ação médica?

Durante séculos, perdurou a ideia de que a decisão do profissional devia prevalecer sobre a vontade da pessoa afetada pela ação de saúde. É certo que os paciente não eram meros objetos, nem os médicos agentes insensíveis, mas é igualmente correto afirmar que a vontade do paciente não era um dado relevante na tomada de decisão médica. ${ }^{1}$

Esse modelo ou paradigma para pensar as questões clínicas passou a ser chamado de hipocrático em razão das máximas morais cunhadas por Hipócrates de Cós em seu Juramento. Nele, o foco principal da ética médica repousa na obrigação do médico de proporcionar aos pacientes benefícios e de protegê-los com a máxima excelência, o que significa que, por vezes, é necessário tomar decisões contra os desejos do paciente, principalmente, quando estes são considerados inadequados ou irracionais segundo a visão do profissional.

O modelo de medicina hipocrática centra-se na máxima do juramento de: "ajudar os doentes de acordo com minha capacidade e julgamento, mas nunca para causar danos ou malefícios." (Cf. HIPPOCRATES, 1957, p. 299, grifo nosso). A lógica moral desse modelo tem como mandamentos primordiais: não causar danos e, quando possível, fazer o bem - non nocere e bonun facere. E não há, a priori, nada de errado, em termos morais, no fato de querer atuar em prol dos outros para o seu bem. O problema está em supor o que é "melhor" sem de fato sabê-lo ou atuar em detrimento dos desejos expressos da pessoa, desde que minimamente razoáveis. Por isso é que o paradigma hipocrático de medicina está fundamentado em certa noção de paternalismo moral, pois se sustenta na "[...] crença de que pode ser correto disciplinar a vida dos outros para o seu próprio bem, independentemente de seus próprios desejos ou julgamentos." (HARRIS, 2001, p. 193-194, tradução nossa).

Somente no século XX e, em especial, a partir da segunda metade, o direito de autodeterminação do paciente emergiu como uma nova realidade da relação médico-paciente. Esse direito se consolidou na prática do consentimento informado ou do consentimento livre e esclarecido.

Inicialmente o consentimento informado surge como resultado de progressivos processos judiciais nos tribunais norte-americanos (Cf. KATZ, 2002, p. 49-83; BEAUCHAMP; FADEN,

1 O Código de Moral Médica brasileiro de 1929 é exemplificativo, pois estabelecia no seu artigo 4 que: "o médico, em suas relações com o enfermo, procurará tolerar seus caprichos e fraquezas enquanto não se oponham as exigências do tratamento, me, [ipsis litteris] exerçam uma influência nociva ao curso da afecção". Disponível em: http://www.portalmedico.org.br/arquivos/codigo_moral_medica(1929).pdf. Acesso em: 20 dez. 2014. 
1986, p. 199 e ss.; LOPES JUNIOR, 2018, p. 72-90), mas logo extrapola as fronteiras daquele país e dissemina-se como um fenômeno geral nos países ocidentais na oposição ao modelo hipocrático de medicina e no avanço dos direitos básicos de proteção ao paciente em sua liberdade e autonomia.

O avanço da ciência médica, a obtenção de diagnósticos cada vez mais precisos, bem como o surgimento no séc. XX de um novo modelo de medicina empresarial, acabam por moldar um novo paradigma para as relações médico-paciente. Tal modelo tem por base o respeito à autonomia do paciente. Nesse novo paradigma, a decisão final sobre as práticas de saúde precisa levar em consideração a vontade do paciente, que passa a ser o detentor da palavra final sobre seu corpo e sua saúde.

A obtenção do consentimento do paciente na relação clínica é uma realidade recente no Brasil. Conquanto ainda não haja uma lei específica para regulamentar a matéria, a jurisprudência pátria já reconhece sua eficácia normativa. No âmbito jurídico, a primeira decisão que reconheceu a necessidade da obtenção do consentimento informado foi proferida pelo Superior Tribunal de Justiça (STJ) e ocorreu no ano de 2002 (Cf. PITHAN, 2012), o que, para a consolidação de um conceito, ainda é algo relativamente recente, sobretudo quando se considera que foi necessário um pouco mais de cinquenta anos para que essa prática fosse consolidada na jurisprudência norte-americana (BEAUCHAMP; FADEN, 1986, p. 125-130).

Em virtude desse desenvolvimento tardio da noção no Brasil, pesquisamos as decisões judiciais tomadas entre os anos de 2002 a 2016 pelo Tribunal de Justiça do Estado do Rio de Janeiro (TJRJ) a respeito do consentimento informado. Nessa pesquisa, utilizando o descritor "consentimento informado", obtivemos um total de 61 (sessenta e uma) decisões, das quais apenas 46 (quarenta e seis) tratavam verdadeiramente de casos de consentimento informado na relação médico-paciente, nos demais eventos, 15 (quinze) no total, o conceito ou a expressão foram utilizados em outro contexto fático ou em relações não entabuladas entre pacientes e médicos.

A análise dos dados também revelou algumas dificuldades, como a utilização da expressão e do conceito "consentimento informado" em situações fora da relação médico-paciente, a dificuldade existente entre a prática real do consentimento informado e sua formalização, a interpretação de que o consentimento do paciente poderia ser presumido em face de fatos e circunstâncias, dentre outros aspectos aptos a fomentar incertezas jurídicas na concretização desse direito.

Por outro lado, é possível comemorar certos avanços na consolidação desse direito ao observar a prática judicial. Por exemplo, o número significativo de condenações, se, à primeira vista, é um dado negativo do ponto de vista da prática clínica, representa um reconhecimento do direito de autodeterminação do paciente; a verificação de que muitos Termos de Consentimento Informado (TCI) foram considerados inadequados quando redigidos de maneira genérica ou quando não trouxeram algumas informações fundamentais em razão das especificidades do caso concreto; o entendimento de que o consentimento informado 
é um dever ético-jurídico independentemente das regras da boa técnica médica (leges artis), dentre outros fatores.

Enfim, o objetivo deste artigo é apresentar um panorama sobre o entendimento jurídico atual do consentimento informado na prática judicial fluminense, associando os dados coletados à revisão da literatura sobre o tema, a fim de verificar como a prática judicial tem contribuído na consolidação do direito de autodeterminação do paciente, bem como quais são as dificuldades que ainda precisam ser superadas.

\section{CONCEITO E ELEMENTOS DO CONSENTIMENTO INFORMADO}

Consentimento informado consiste na manifestação do direito de autodeterminação dos pacientes nas relações médicas, por um lado, bem como no dever dos profissionais de saúde de respeitar a autonomia do paciente no âmbito clínico e no de pesquisas com seres humanos, por outro. Isso traz como consequência o fato de que os profissionais de saúde devem, além de esclarecer o quadro clínico e as consequências do tratamento, obter autorização do paciente para atuar, a fim de que o ato médico traduza os verdadeiros interesses e valores das pessoas afetadas.

Ainda que se possa conceber o consentimento informado como sendo uma decisão compartilhada entre médico e paciente, ${ }^{2}$ Beauchamp e Faden (1986) sustentam que esse pressuposto é difícil de ser aferido na prática, sendo mais importante que a decisão tenha sido, de fato, autorizada pelo paciente de acordo com a voluntariedade do seu querer.

O consentimento informado pode ser definido como uma autorização autônoma para uma intervenção médica ou para uma pesquisa médica com pacientes. Essa autorização autônoma precisar ser mais que uma mera aquiescência do paciente para o médico atuar de determinada forma ou para o pesquisador prosseguir com sua pesquisa; ela requer uma compreensão substancial e uma ausência de pressão externa para que a declaração de vontade traduza de fato a intencionalidade do paciente, isto é, para que sua declaração seja o espelho de seus interesses concretos e de seus valores (BEAUCHAMP; FADEN, 1995, p. 1279, tradução nossa).

Alguns elementos merecem destaque, pois acabam constituindo verdadeiros requisitos para a prática do consentimento informado (BEAUCHAMP; FADEN, 1986, p. 274), são eles: revelação da informação, compreensão, voluntariedade, competência (ou capacidade) e consentimento.

Esses requisitos podem ser classificados em pré-condições (competência e voluntariedade); elementos de informação (revelação da informação e da compreensão) e elemento de consentimento (consentimento propriamente dito ou autorização).

2 Por exemplo, Jay Katz explica que "os médicos que acreditam que os pacientes são parceiros desiguais no processo de tomada de decisão médica [...]. A insistência na autoridade coloca fim a qualquer inferência séria sobre se os médicos e seus pacientes poderiam interagir uns com os outros com base em maior igualdade. Assim, a ideia de consentimento informado - de tomada de decisão mútua - permanece gravemente comprometida." (KATZ, 2002, p. 87, tradução nossa, grifo nosso). 


\subsection{PRÉ-CONDIÇÕES: COMPETÊNCIA PARA A DECISÃO E A VOLUNTARIEDADE}

\subsubsection{Competência para decidir em questões de saúde}

A decisão do paciente deve corresponder a sua vontade autônoma, e, para que a vontade emanada possa produzir efeitos jurídicos válidos, a pessoa deve ser competente para decidir. A questão da competência é uma pré-condição para aferir se a vontade emanada do sujeito é juridicamente válida. Dessa forma, o requisito da competência impõe a análise da vontade juridicamente qualificada. ${ }^{3}$

No direito brasileiro, o critério de competência é estabelecido pela capacidade jurídica de fato, que é um atributo de todas as pessoas que podem exercer por si só os atos da vida civil. O Código Civil estabelece a capacidade plena aos maiores de 18 anos de idade ou aos emancipados, nas hipóteses previstas no art. 5º, porém algumas circunstâncias fáticas podem relativizar a capacidade de fato (art. 4o do Código Civil Brasileiro), como a idade entre 16 e 18 anos, a impossibilidade transitória ou permanente de exprimir a vontade e a dependência do uso de drogas. ${ }^{4} \mathrm{Na}$ ocorrência de uma dessas situações, a pessoa passa a ser considerada relativamente capaz, o que, em termos práticos, exige a nomeação de um tutor, para a primeira hipótese, ou de curador, para os demais casos. Essas pessoas são nomeadas a partir de uma decisão judicial para substituírem o processo de tomada de decisão do relativamente incapaz.

Além disso, o Código Civil Brasileiro não reconhece qualquer validade aos atos praticados pelos menores de 16 anos (art. 3o), que são, por isso, classificados como incapazes. Logo, a tomada de decisão que envolva incapazes deve ser feita por meio de seus representantes legais: pais ou tutores.

Cumpre ressaltar que a capacidade definida como um atributo da idade biológica vem sendo tratada em outros países de forma diferenciada quando a decisão é atinente ao direito à saúde, distinguindo esse tipo de decisão daquelas que são meramente patrimoniais.

$\mathrm{Na}$ Alemanha, por exemplo, enquanto a capacidade plena ocorre aos 18 anos, a capacidade para realização de contratos patrimoniais já começa aos 7 anos, havendo a necessidade de menor ser assistido para que a declaração produza efeitos válidos (Art. 104,1 do Código Civil Alemão). Já a capacidade para tomar decisões médicas segue um padrão da "escala móvel"

3 André Gonçalo Dias Pereira explica a distinção, pois a capacidade para tomar decisões médicas, isto é, para tomar decisões relativas aos direitos da personalidade, que afetam a vida, a integridade física e a saúde, deve ser tratada como uma capacidade à parte da capacidade delitual e negocial. "Trata-se de um ramo da capacidade jurídica, cujo objeto é o de tomar decisões sobre os cuidados de saúde, isto é, a capacidade para consentir ou recusar um tratamento médico. Sendo uma figura paralela à capacidade negocial, não se deve com esta confundir. Embora me incline para não abandonar a nomenclatura clássica: capacidade / incapacidade, a verdade é que na literatura de ética médica e da bioética, onde há muito se discerne este instituto, utiliza-se o termo (aparentemente um anglicismo) 'competente / incompetente', 'competência / incompetência'” (PEREIRA, 2004, p. 153).

$4 \mathrm{O}$ artigo $4^{\circ}$ do Código Civil Brasileiro ainda prevê como causas dessa relativa incapacidade a prodigalidade, mas essa psicopatologia não afeta o exercício dos direitos da personalidade, mas tão-somente as decisões relacionadas ao patrimônio, não incapacitando a pessoa de tomar uma decisão médica. 
(Cf. BEAUCHAMP; FADEN, 1986, p. 290), que consiste em um teste de compreensão das habilidades cognitivas levando em consideraçãoa idade e a aptidão para entender a complexidade da intervenção recomendada (art. 630d do Código Civil Alemão). O mesmo ocorre nas legislações da Holanda e da Bélgica, países que adotam sistemas de escala para a capacidade quando as decisões afetam direitos da personalidade (Cf. PEREIRA, 2004, p. 146 e ss.). Essa conduta também pode ser encontrada na lei espanhola de direitos do paciente (2002). ${ }^{5}$

\subsubsection{Voluntariedade}

Voluntariedade refere-se ao direito de o paciente tomar decisões sobre tratamentos médicos sem que sua vontade seja manipulada ou obtida por coerção (Cf. DYKEMAN; DEWHIRST, 2008, p. 31).

A voluntariedade é um conceito complexo, que se correlaciona com outros, como a liberdade, a autonomia e a independência. Beauchamp e Faden (1986, p. 239) sustentam que, enquanto a autonomia pode ser colocada como uma questão de graus, isto é, enquanto uma ação pode ser considerada mais ou menos autônoma em relação à compreensão que o sujeito possui sobre o conjunto de informações importantes para a tomada da decisão, a voluntariedade não admite essa análise gradativa. Os referidos autores adotam voluntariedade no mesmo sentido de intencionalidade da ação e, nesse sentido, explicam citando o filósofo escocês Thomas Reid que:

[t]oda pessoa inevitavelmente sabe que o que é feito por sua vontade consciente e intenção, deve ser reputado a si própria [...] e que, [ao contrário] tudo que é feito sem vontade consciente e sem intenção não pode ser verdadeiramente atribuído a si próprio. Se ele tencionou e quis, sua ação pode ser julgada como ato humano. Mas se foi realizado sem seu conhecimento, ou sem o concurso de sua vontade ou intenção, é tão certo que não o realizou, como não o quis ou tencionou (REID apud BEAUCHAMP; FADEN, 1986, p. 242, tradução nossa).

Antes de qualquer coisa, a voluntariedade, tal como concebida por Reid, deve ser distinguida da intencionalidade pura. Não se trata apenas de querer algo sem que isso se traduza em um plano de ação. A intencionalidade pura pode ocorrer sem que se materialize em qualquer domínio de ação, por isso essa noção somente importa na medida em que ela se integraliza em um plano de ação, ou seja, quando se torna um referencial ou uma representação de estratégias e táticas para a realização da ação: "[p]ara que um ato seja intencional, deve corresponder à concepção do autor do ato em questão (embora o resultado planejado possa não ocorrer).” (BEAUCHAMP; FADEN, 1986, p. 242).

A falta de voluntariedade contraria aquilo que o paciente desejava inicialmente e o

5 Art. 5०, 3०. - "Cuando el paciente, según el criterio del médico que le asiste, carezca de capacidad para entender la información a causa de su estado físico o psíquico, la información se pondrá en conocimiento de las personas vinculadas a él por razones familiares o de hecho." (ESPANHA, 2002, online). 
que foi objeto de deliberação e anuência de sua parte. Voluntariedade corresponde, assim, à identificação do resultado da ação ou do ato praticado com a concepção inicial do paciente, embora, obviamente, esse nexo possa ser rompido por um evento fortuito, uma intercorrência médica (LOPES JUNIOR, 2018, p. 272). Dessa maneira, a falta de voluntariedade admite como exceção as situações de emergência médica, ${ }^{6}$ as quais se caracterizam pela impossibilidade de obtenção em tempo hábil da autorização do paciente ou de seus representantes legais.

É possível que, em algumas situações, a divergência entre a ação realizada e o plano de ação escolhido dependa de uma análise qualitativa quanto à finalidade do ato pretendido. Uma ação pode desviar-se de seu plano inicial de forma trivial, não afetando significativamente o resultado previsto, ou, ao contrário, de maneira essencial. Neste último caso, não haveria voluntariedade nem autonomia, a fortiori, nem consentimento válido.

Voluntariedade é pré-requisito, porque é causa motivadora do agir; vincula-se ao fim a que visa a ação, logo, sem voluntariedade, não há ação autônoma. Como Dykeman e Dewhirst (2008) bem salientam, voluntariedade entrelaça autonomia, liberdade e independência.

Como requisito do consentimento informado, sua violação não só retira a autonomia do processo decisório, mas vai além, atenta contra a liberdade da pessoa de poder decidir sobre uma situação médica.

Das 46 (quarenta e seis) decisões encontradas no TJRJ, três delas tratavam de problemas relativos à falta de voluntariedade, o que representa um percentual baixo dentro dos dados coletados, $6,52 \%$. As ocorrências são esparsas ao longo do tempo, sendo um caso datado do ano de 2003, outro de 2007 e o último de 2013.

A decisão datada de 2003 trata de um caso de retirada de uma das trompas de falópio sem o prévio consentimento da paciente. De acordo com a descrição dos fatos trazida na decisão, a paciente consentira com a realização de uma videolaparoscopia, com o intuito diagnóstico, mas, com ele já em curso, o médico entendeu que era a trompa direita da paciente precisava ser retirada. Contudo, o profissional não obteve a anuência da paciente para essa intervenção. $\mathrm{O}$ único documento que a paciente assinara fora um termo de responsabilidade genérico no qual estava consignado: "Autorizo o Corpo Clínico desse Hospital a proceder exames clínicos, laboratoriais e tratamentos clínicos ou cirúrgicos que se fizerem necessários, inclusive transfusões de sangue”. (BRASIL, 2003, online).

Esse é outro fato importante a ser destacado na análise das decisões judiciais. Em 10 (dez), dos 46 (quarenta e seis) casos analisados, os TCI's assinados pelos pacientes foram considerados inadequados para comprovar que, de fato, eles estavam cientes do procedimento médico e de seus riscos.

No caso acima, o relator do processo condenou o profissional por ausência de consentimento informado e sublinhou que "o ser humano é senhor do seu corpo. A sua integridade física é direito indisponível." (BRASIL, 2003, online). De fato, o consentimento da paciente

6 Artigo 31 do Código de Ética Médica (Resolução CFM 2.217 de 27 de setembro de 2018): "Desrespeitar o direito do paciente ou de seu representante legal de decidir livremente sobre a execução de práticas diagnósticas ou terapêuticas, salvo em caso de iminente risco de morte". 
foi viciado, não por falta de informação sobre os riscos, mas pela ausência de autorização para o procedimento realizado. A paciente, que já havia retirado a trompa esquerda em procedimento médico anterior, queria obter um diagnóstico mais preciso para saber suas chances reais de engravidar. No entanto, o procedimento realizado sem sua autorização retirou por completo essa opção.

Já o caso de 2013 tratou de uma cirurgia estética para implantação de prótese mamária. O cirurgião adotou técnica diversa da que foi pactuada com a paciente, impossibilitando-a de deliberar sobre eventuais riscos dela decorrentes. Dessa forma,

[...] a paciente consentiu com determinada técnica (“T” invertido), porém o cirurgião aplicou técnica diversa, sem colher o prévio consentimento da autora, conduta que viola não apenas o dever de informação previsto no art. $6^{\circ}$, III, do CDC, como também o princípio do consentimento informado, que traduz o direito do paciente de participar de toda e qualquer decisão sobre tratamento que possa afetar sua integridade psicofísica, devendo ser alertado pelo médico dos riscos e benefícios das alternativas envolvidas, sendo manifestação do reconhecimento de que o ser humano é capaz de escolher o melhor para si sob o prisma da igualdade de direitos e oportunidades (BRASIL, 2013a, online).

Os casos acima evidenciam que a revelação das informações na relação clínica não pode ser conduzida com base em modelos puramente abstratos. Ainda que seja possível enumerar riscos e intercorrências comuns, os termos devem estar abertos para incluírem as especificidades do caso concreto, isto é, as características da doença que acomete a paciente e as circunstâncias que circunscrevem seu quadro clínico. Como observa Pereira (2004, p. 536), a informação padronizada não pode prevalecer sobre as circunstâncias concretas do paciente em cada caso, afastando-se das particularidades gerais da patologia concernida ou deixando de representar a relação tipicamente dialógica básica para a formação de um consentimento informado. Ainda que existam informações genéricas, elas devem ser completadas pelas circunstâncias particulares do paciente concretamente considerado e do seu quadro clínico.

A voluntariedade é condição primária para o consentimento informado, pois, como procuramos destacar, não se trata de um problema atinente aos requisitos de esclarecimento em si, mas de poder decidir sobre o que ocorre com seu próprio corpo. Trata-se de violação à liberdade de escolha, uma vez que o procedimento médico realizado poderia ser objeto de deliberação do paciente, configurando divergência entre o que se realizou e aquilo que foi previamente consentido.

Nesse ponto, a judicialização do direito de autodeterminação é sensível a esse tipo de violação, pois é flagrante que não se pode garantir processo decisório autônomo quando os atos são praticados unilateralmente. 


\subsection{ELEMENTOS DE INFORMAÇÃO}

Para que uma decisão seja substancialmente autônoma (Cf. BEAUCHAMP; FADEN, 1986, p. 241)7 é necessário que o paciente seja esclarecido de forma adequada, com o uso de uma linguagem compreensível sobre o diagnóstico, o prognóstico e seus riscos, bem como sobre eventuais opções terapêuticas alternativas, quando existentes.

Primeiramente, a análise consiste em saber se, minimamente, o paciente foi advertido sobre os benefícios e os riscos da intervenção médica. Em segundo lugar, saber se a informação de fato foi adequada, isto é, se ela foi apta a gerar uma decisão substancialmente autônoma, sem que tenha havido o desvirtuamento intencional na informação sobre o diagnóstico ou o prognóstico da doença.

O primeiro caso restringe-se à mera questão de saber se o paciente foi advertido sobre os riscos. O que vemos é que dos 46 (quarenta e seis) casos encontrados, 33 (trinta e três), $71,74 \%$, acarretaram condenações dos profissionais por esse vício no consentimento. Já o segundo caso seria aquele em que o profissional, na sua comunicação, superestima ou subestima os riscos de um procedimento, gerando no paciente uma falsa compreensão da realidade. ${ }^{8}$ Só verificamos um caso nas decisões analisadas, sobre essa segunda modalidade.

A ausência da revelação de informações, por si só, já constitui uma violação aos direitos da personalidade. ${ }^{9}$ Independentemente das consequências, a pessoa deve estar apta a tomar uma decisão autônoma. Um paciente que decide sem estar devidamente esclarecido toma uma decisão livre, mas não uma decisão [substancialmente] autônoma, pois autorizou procedimento sem ter pleno conhecimento das consequências.

7 A autonomia substancial é aquela que apresenta um objetivo razoável e alcançável; representa um limiar apropriado entre os ideais extremos (entre a coerção e a persuasão) para a tomada de decisão nas intervenções médicas - embora a teorização seja válida para as demais esferas da ação humana. O modelo de ação substancialmente autônoma deve ser adotado, de acordo com os autores, como padrão necessário para aferir o consentimento informado na relação médico-paciente; é considerado um padrão necessário porque a decisão, nessas condições, é viável de ser alcançada por qualquer paciente, e os profissionais de saúde estariam obrigados a criar condições para sua eficácia. Isso significa que fora da esfera da autonomia substancial ou haveria uma violação do consentimento informado, na medida em que a ação ultrapassasse o limite do não controle/ não entendimento, ou não seria exigível um empenho dos profissionais em garantir um total entendimento e controle das circunstâncias pelo paciente. O modelo de autonomia substancial compartilha o entendimento amplamente aceito de que a compreensão do paciente é um requisito para o consentimento informado. Situada dentro dos limites da autonomia empiricamente viável, a compreensão do paciente deve ser substancial. Isso envolve considerar não só a intencionalidade da ação, mas também a autorização do paciente para o procedimento médico

8 Conforme estabelece o Código de Ética Médica (Resolução CFM 2.217, de 27 de setembro de 2018), em seu artigo 35, que estabelece ser vedado ao médico: "Exagerar a gravidade do diagnóstico ou do prognóstico, complicar a terapêutica ou exceder-se no número de visitas, consultas ou quaisquer outros procedimentos médicos".

9 Revelação da informação refere-se, portanto, ao processo de fornecimento de informações por parte dos profissionais de saúde sobre um diagnóstico ou um tratamento médico proposto ao paciente. A revelação, unida à capacidade, à compreensão e à autorização, constitui os elementos fundantes do consentimento informado (D'AGINCOURT-CANNING; JOHNSTON, 2008, p. 4). 
Para Beauchamp e Faden (1986), o requisito “compreensão" é um elemento-chave para a prática do consentimento informado, pois, uma vez satisfeito, parte-se da suposição de que a intencionalidade e a autorização não apresentariam problemas. Entretanto, os autores advertem que essa suposição não possui uma relação de necessariedade, porque podem ocorrer situações em que haja uma perfeita compreensão sem que estejam satisfeitas as condições de intencionalidade e autorização. No entanto, tais situações são mais hipotéticas do que concretas, conforme explicam os autores, "[é] difícil imaginar um cenário plausível em que o consentimento do paciente para a cirurgia X não seria intencional, se o paciente, adequadamente esclarecido, tenha consentido com a cirurgia X." (BEAUCHAMP; FADEN, 1986, p. 243, tradução nossa). Dessa forma, devido a essa relação imbricada entre intencionalidade, compreensão e autorização, se a condição de compreensão estiver satisfeita, há boas razões para supor que o ato de autorização do procedimento é autônomo.

É muito difícil criar uma listagem descritiva de ações humanas e de circunstâncias passíveis de serem consideradas como representativas de uma “compreensão adequada", até porque algumas informações médicas podem ser consideradas relevantes para uma pessoa e triviais para outra. Grande parte dos esforços, pelo menos do ponto de vista jurídico - que deve ser uma preocupação do profissional de saúde -, reside na tentativa de traçar uma distinção entre informações prescindíveis/imprescindíveis para o consentimento informado.

Frisch (2004) apresenta uma análise acurada da informação prestada ao paciente para uma intervenção médica. Para esse autor, o paciente só está apto a decidir quando for suficiente informado sobre a natureza e a envergadura da intervenção, o que gera o dever de informar sobre:

a) os riscos da intervenção;

b) suas circunstâncias e;

c) os riscos associados.

Em primeiro lugar, a informação deve abarcar os riscos da intervenção, o que compreende as possíveis desvantagens a ela inerentes, como as dores previsíveis, o tempo necessário para o reestabelecimento, as limitações ou as perdas funcionais, as eventuais agravações de determinados processos e as sequelas futuras.

Em segundo lugar, as circunstâncias do caso clínico devem ser expostas a fim de que o paciente possa decidir sobre a necessidade e as razões da intervenção, como o porquê de o procedimento ser urgente e necessário, se existem outras opções e quais as chances de sucesso de cada uma delas.

Por fim, a informação deve compreender os riscos associados, que não se verificam em toda e qualquer operação, bem como os riscos específicos para o paciente e seu particular modo de vida, desde que conhecido pelo médico.

Riscos associados, tal como descritos por Frisch, colocam em evidência o fato de que a informação a ser prestada não está ligada apenas a aspectos objetivos (circunstâncias), como a natureza de uma eventual patologia, as consequências adversas de um tratamento, o tempo de 
recuperação etc., mas também aos interesses e aos objetivos de cada paciente particular. Por exemplo, em uma cirurgia estética embelezadora em que uma paciente quer aumentar o tamanho dos seios, uma possível consequência pode ser a perda da capacidade de amamentação. Essa informação pode ser irrelevante ou trivial para uma mulher que realizou uma laqueadura tubária, mas imprescindível para uma paciente jovem que futuramente deseja ter filhos.

O que podemos constatar pela análise das decisões judiciais é que a falta de atenção dos profissionais para os riscos associados, para a informação individualizada e munida de aspectos circunstanciais da intervenção considerada, é responsável por um número significativo de condenações (LOPES JUNIOR, 2018, p. 114-134; p. 397-402). Por essa razão, Beauchamp e Childress (2011, p. 171) explicam que a revelação da informação deve seguir um modelo subjetivo, pois a informação deve ser adequada ao paciente concretamente considerado, a fim de incluir informações que talvez não fossem relevantes para um "paciente médio", mas que seriam primordiais para o paciente concreto. Nesse modelo, a revelação da informação está centrada no paciente individualizado, que toma a decisão de acordo com seus próprios interesses. Interesses que nem sempre coincidem com os dos demais pacientes em geral.

A revelação adequada da informação é um problema que aparece em muitos dos casos analisados, pois, como se afirmou, 71,74\% das decisões tratam de informações prestadas de forma inadequada. Entretanto, em 21,74\% delas, 10 (dez) ao todo, os profissionais foram condenados por violação ao consentimento informado muito embora os pacientes tenham assinado um TCI. Isso ocorreu, em geral, porque os termos foram considerados genéricos, não traduzindo a realidade do paciente ou os riscos do procedimento a que ele se submeteria.

Por exemplo, em uma decisão de 2009, o paciente submeteu-se a uma ritidoplastia, a qual resultou em uma lesão do nervo facial. O TCI foi considerado inadequado porque foi considerado "genérico, aplicável a qualquer cirurgia, seja plástica ou não, há lacunas a serem preenchidas, como o objetivo e o propósito da cirurgia, e, principalmente, não há nenhuma menção as principais, ou, pelo menos, as mais frequentes, complicações desta cirurgia.” (BRASIL, 2009a, p. 4).

Problema semelhante ocorre quando a informação é prestada de forma incorreta, levando à criação de falsas expectativas. As expectativas criadas pelo profissional influem sobre o processo de deliberação do paciente, quer porque aumentam a certeza da produção de um resultado positivo para intervenção, quer por superestimar os riscos dos efeitos negativos, quer, simplesmente, porque as informações são prestadas inadequadamente pelo profissional.

Os problemas agravam-se quando da expectativa frustrada advêm consequências danosas para o paciente. É um exemplo desse fato uma decisão datada de 2008 (BRASIL, 2008), na qual a paciente, grávida, ao realizar seus exames de pré-natal, recebeu o diagnóstico positivo para o vírus HIV. Quatro dias após o recebimento do diagnóstico, já começou o tratamento para a doença, ingerindo uma alta dose de medicamentos retrovirais. A realização de um novo exame acusou o falso positivo, mas isso ocorreu após três meses. Nesse ínterim, a paciente entrou em trabalho de parto, e a laqueadura tubária foi feita por indução de seu médico, que 
a recomendou devido a seu "quadro clínico". Fora isso, sublinha-se que o segundo exame foi feito tanto na paciente quanto em seu marido, mas o dele foi entregue dois meses antes do dela, com o resultado negativo, o que ocasionou a separação do casal pela desconfiança gerada na relação.

Os problemas de informação na relação médico-paciente são numerosos e certamente os mais evidentes na prática judicial. Essa é a razão por que muitos operadores do direito associam a prática do consentimento a um problema de prestação de informação médica. Contudo, o consentimento informado não se esgota no problema da informação prestada ao paciente, como sustentamos acima, requerendo também autorização e voluntariedade para o ato praticado.

\subsection{CONSENTIMENTO PROPRIAMENTE DITO OU AUTORIZAÇÃO PARA O ATO MÉDICO}

Quando uma pessoa escolhe algo, recusa ou concorda com alguma coisa ou ação, é possível identificar essas condutas como sendo espécies abrangentes de ação autônoma. Contudo, é um erro considerar o consentimento informado como um sinônimo de ação autônoma. O consentimento é um tipo de ação autônoma que possui elementos específicos. Para Beauchamp e Faden (1986, p. 277), o que singulariza o consentimento informado é a autorização autônoma que o paciente fornece ao profissional para realizar um procedimento médico ou para ser sujeito de pesquisa.

Os autores explicam que uma pessoa pode assentir com um tratamento sem que necessariamente o tenha autorizado, por mais contraditório que possa parecer. $\mathrm{O}$ assentimento pode, por exemplo, ter resultado de uma pressão do profissional sobre o paciente; nesse caso, o paciente não se vale de sua própria autoridade para dar a permissão, e, consequentemente, o ato não tem sua autorização (BEAUCHAMP; FADEN, 1986, p. 278).

É nesse sentido que o Consentimento Informado, como outrora já definimos, consiste em uma autorização autônoma dada por um paciente ou por um sujeito de pesquisa. Isso significa que a pessoa possui entendimento substancial do ato e de suas consequências e não sofre coação para essa autorização.

A autorização dá ao outro partícipe da relação a permissão e a responsabilidade para proceder. Dependendo das circunstâncias, X autoriza Y a realizar I, significa que $\mathrm{X}$ e Y compartilham a responsabilidade pela consequência de I ou que a responsabilidade é inteiramente de X (assumindo, claro, que $\mathrm{Y}$ tenha executado I de modo diligente). (BEAUCHAMP; FADEN, 1986, p. 280, tradução nossa).

Autorização é ato final do processo de consentimento informado, pressupõe entendimento do ato e voluntariedade na sua execução. É possível elencar duas situações em que o problema do consentimento informado está na falta de autorização: primeiro, quando o paciente não é informado antes do procedimento sobre intercorrências que são relativamente habituais. No nosso entendimento, intercorrências previsíveis que dão ensejo a intervenções 
cirúrgicas no curso de outro procedimento são violações ao consentimento informado, pois, se a intercorrência é previsível, o paciente deveria ter a oportunidade de deliberar sobre essa opção. Segundo, constituem clara violação ao consentimento informado os atos médicos que vão de encontro ao que o paciente expressamente deseja, como ocorre nas transfusões compulsórias de sangue em pacientes testemunhas de Jeová.

\section{AVANÇOS E DIFICULDADES DO CONSENTIMENTO INFORMADO NA PRÁTICA JUDICIAL FLUMINENSE}

O consentimento informado é um padrão ético-normativo exigível para as relações médico-paciente no âmbito clínico e nas pesquisas com seres humanos. Seu conceito e sua função, no entanto, estão ligados a determinados valores que fundamentam os direitos fundamentais da pessoa humana: seu corpo, sua liberdade, sua privacidade, seus interesses e seus projetos individuais de vida. Nesse sentido, ao se assumir a prática do consentimento informado como um valor positivo na relação médico-paciente, a ordem jurídica nega legitimidade a práticas consideradas paternalistas e coloca o indivíduo e seus direitos fundamentais no centro da relação jurídico-privada.

A análise da judicialização da relação médico-paciente, em especial no que toca ao consentimento informado, revela a conscientização da importância desse direito por parte do Poder Judiciário. No que tange às decisões do Tribunal de Justiça do Estado do Rio de Janeiro (TJRJ), as violações comprovadas no curso dos processos judiciais ao consentimento informado foram muito superiores às absolvições. Longe de celebrar o fato de que violações são, por si, um valor positivo, elas expressam, por seu turno, a eficácia ${ }^{10}$ e o reconhecimento do direito de autodeterminação dos pacientes pelo sistema jurídico.

Tabela 1 - Resultado das decisões judiciais sobre CI entre os anos de 2002-2016 do TJRJ

\begin{tabular}{llll}
\hline Resultado dos Processos Judiciais & \multicolumn{1}{l}{ TOTAIS } & $\%$ \\
\hline 1. Condenação por ausência de CI & 27 & $56,25 \%$ \\
\hline 2. Houve condenação por ausência de CI, embora presente o TCI & 10 & $20,83 \%$ \\
\hline 3. Houve consentimento puramente verbal ou presumido (não há TCI) & 4 & $8,33 \%$ \\
\hline 4. Não houve condenação (respeitado o procedimento de CI) & 5 & $10,42 \%$ \\
\hline & 46 & $100,00 \%$ \\
\hline
\end{tabular}

Os itens 1 e 2 apresentam o total das condenações, juntos chegam a 77\% do total dos casos analisados. Essas condenações levaram em consideração a violação ao Consentimento Informado $(\mathrm{CI})$, por não terem sido objeto de consideração na relação médico-paciente, isto é, por não terem sua prática comprovada (item 1) ou porque, embora tenha sido apresentado

10 A eficácia de uma norma não deve ser medida apenas pelo grau de respeito a que se presta ao seu preceito conteúdo da norma - mas também ao fato de que eventuais frustrações às expectativas da norma são refeitas pela aplicação da sanção que a norma comporta. Nesse caso, com a reparação ao dano causado aos direitos da personalidade (Cf. SABADELL, 2005, p. 63-64). 
um TCI, ele foi considerado genérico ou insuficiente no processo de revelação da informação ao paciente (item 2).

Os itens 3 e 4, por seu turno, trazem o total de casos em que se alegou a violação ao consentimento informado sem ter havido uma comprovação de sua ocorrência. $\mathrm{O}$ item 3, no entanto, evidencia uma dificuldade real entre a prática material do consentimento informado e a sua comprovação por meio de um documento escrito. O problema está no fato de que não existe no país uma regulamentação específica que determine a forma que o consentimento informado deve assumir, nem de forma geral, muito menos considerando situações específicas da prática clínica. Diferentemente, por exemplo, do que ocorre na Espanha ${ }^{11}$ e na Argentina, ${ }^{12}$ apenas para citar alguns padrões.

A legislação brasileira é omissa tanto em relação ao conteúdo do consentimento informado quanto à forma de sua instrumentalização. As regulamentações restringem-se basicamente ao art. 15 do Código Civil Brasileiro (CC) e a alguns dispositivos do Código de Ética Médica (CEM) (BRASIL, 2019), os quais não são suficientes para fornecer um parâmetro adequado para criar segurança jurídica ideal. Essa anomia cria dificuldades para os operadores do direito, para os pacientes e para os profissionais de saúde.

O artigo 15 do CC estabelece que "ninguém pode ser constrangido a submeter-se, com risco de vida, a tratamento médico ou a intervenção cirúrgica.” (BRASIL, 2002, online). A generalidade da redação desse preceito normativo não fornece parâmetros adequados para ninguém pode ser constrangido a submeter a prática correta do consentimento informado, isso ocorre porque o referido dispositivo não faz referência ao instituto; não trata do direito do paciente de ser esclarecido no âmbito biomédico; não faz alusão à autonomia como valor fundamental; nem tampouco define ou orienta a aplicação do direito de autodeterminação, como em que casos a autorização deve ocorrer por escrito ou verbalmente, não trata do processo de substituição do processo de tomada de decisão em casos de incompetência etc.

O CEM, por sua vez, regulamenta a prática do consentimento informado em diversos dispositivos, sendo mais representativa para a noção a regra que proíbe o médico de "deixar de obter consentimento do paciente ou de seu representante legal após esclarecê-lo sobre o

11 Assim estabelece a Lei espanhola n. 41 de novembro de 2002: Art. 2, item 2: "2. Toda actuación en el ámbito de la sanidad requiere, con carácter general, el previo consentimiento de los pacientes o usuarios. El consentimiento, que debe obtenerse después de que el paciente reciba una información adecuada, se hará por escrito en los supuestos previstos en la Ley". Bem como no seu Art. 8, item 2: "El consentimiento será verbal por regla general. Sin embargo, se prestará por escrito en los casos siguientes: intervención quirúrgica, procedimientos diagnósticos y terapéuticos invasores y, en general, aplicación de procedimientos que suponen riesgos o inconvenientes de notoria y previsible repercusión negativa sobre la salud del paciente”. (ESPANHA, 2002, online).

12 De maneira similar à lei espanhola, a lei argentina n. 26.529 de 21 de outubro de 2009 regulamenta a instrumentalização do consentimento informado no seu Art. 7: "El consentimiento será verbal con las siguientes excepciones, en los que será por escrito y debidamente suscrito: a) Internación; b) Intervención quirúrgica; c) Procedimientos diagnósticos y terapéuticos invasivos; d) Procedimientos que implican riesgos según lo determine la reglamentación de la presente ley; e) Revocación”. (ARGENTINA, 2009, online). 
procedimento a ser realizado, salvo em caso de risco iminente de morte".${ }^{13}$ Contudo, é silente quanto à forma que deve assumir o consentimento informado. ${ }^{14}$

Em razão dessa dificuldade prática, o Conselho Federal de Medicina (CFM) emitiu o Parecer n. 22 no ano de 2004:

\begin{abstract}
Quanto ao consentimento informado por escrito, ressalvadas algumas exceções, pouco significado ele tem no campo do ato médico, pois o consentimento não protege nem isenta médicos ou pacientes de resultados desfavoráveis que venha a ocorrer, pois se a parte a quem foi destinado o tratamento sentir-se prejudicada, com ou sem razão, pode atribuir insucesso à conduta faltosa do médico, que há de responder por ela. $\mathrm{O}$ consentimento por escrito deve ser obtido no âmbito da pesquisa, na extirpação de membros, em cirurgias mutiladoras e em outras situações que devem ser avaliadas pelo médico [...] (Parecer CFM n. 22/2004 apud BERGSTEIN, 2013, p. 207, nota 384).
\end{abstract}

Esse parecer equipara a prática do consentimento informado à dimensão técnica do ato médico, sustentando a posição de que o dano ao consentimento estaria vinculado ao dano produzido pelo erro da técnica, o que é um equívoco evidente.

Além disso, não esclarece quais seriam as exceções que deveriam ensejar sua prática por escrito. Então, persiste a seguinte questão: em quais modalidades de ato médico o consentimento deve assumir a forma escrita?

A atividade clínica compreende diversas fases, que passam pelo diagnóstico, pelo prognóstico, podendo ou não seguir para o desenvolvimento de uma terapêutica. Nesse caso, até por força do art. 15 do CC, as práticas invasivas, sejam cirúrgicas, sejam diagnósticas, exigem um cuidado maior na obtenção do consentimento informado, sendo a forma escrita o meio mais adequado para assegurar que a prática foi obedecida. Não restam dúvidas de que todas as etapas da clínica estão subordinadas à obtenção do consentimento do paciente, conforme preceitua o art. 34 do CEM, mas ele deve ser exigido por escrito em todas essas etapas?

As quatro decisões judiciais enquadradas no item 4 da tabela 1 evidenciam essa dificuldade. Essas decisões atestam a inexistência de documento escritos, mas o consentimento do paciente acabou sendo deduzido por outros meios de provas ou simplesmente foi presumido em razão da natureza da intervenção, o que ocorreu, por exemplo, em uma decisão judicial datada de 2007:

Responsabilidade civil. Indenizatória. Ligadura de trompas. Sentença reformada. A Laqueadura somente é feita pelo médico com o consentimento da paciente,

13 Artigo 22 da Resolução CFM 2.217 , de 27 de setembro de 2018 (Código de Ética Médica). (BRASIL, 2019).

14 Aliás, o silêncio é necessário, pois, se a declaração do paciente assume a forma de um ato jurídico em sentido amplo, regulamentar disposições quanto a esse tema seria inconstitucional, uma vez que é de competência privativa da União legislar sobre direito civil. Art. 22, I, da Constituição Federal: "Compete privativamente à União legislar sobre: I - direito civil, comercial, penal, processual, eleitoral, agrário, marítimo, aeronáutico, espacial e do trabalho". (BRASIL, 1988, online). 
contudo, não é necessário que seja dado por escrito, admitindo-se que seja verbal. Não há o que imponha sob a formalidade da literalidade. O procedimento do médico não se mostra desviado da moral e da ética. Ausente vício de consentimento (BRASIL, 2007, p. 3).

Entendimento similar pôde ser encontrado em um caso datado do ano de 2009, em que aconteceu a amputação de parte dos dedos de uma das mãos do paciente que demandava o reimplante. Nesse caso, foram aceitos testemunhos de membros da equipe cirúrgica que confirmaram que o paciente "estava lúcido e fora informado sobre a impossibilidade de reconstrução das mãos, mediante reimplante de dedos, bem como da amputação de parte do membro aludido." (BRASIL, 2009a, p. 3).

Esse tópico se mostra nevrálgico para a consolidação do direito de autodeterminação dos pacientes e apresenta soluções ambíguas. A adoção de um TCI pode ajudar no diálogo, mas não pode substituir a prática real de esclarecimento do paciente, como bem adverte Dias Pereira (2000). O referido autor explica que esse foi o caminho tomado pela prática médica estadunidense, a qual exige o preenchimento de formulários para toda e qualquer intervenção médica. No entanto, isso pode gerar uma série de inconvenientes, por exemplo, a) o funcionamento de um expediente em que os médicos tornem sua rotina célere por meio de um padrão de obtenção de consentimento burocratizado; ${ }^{15}$ b) o formulário pode, muitas vezes, ser considerado insuficiente para comprovar a prática real do consentimento informado, o que faria dele um instrumento probatório questionável. Isso, como já mencionamos, também ocorre em nossa realidade, como atesta o item 2 da tabela 1.

Por outro lado, admitir a prova do consentimento informado por meio oral pode dar margem a interpretações baseadas em presunções que colocariam em risco a segurança desse direito, tal como procuramos evidenciar nos casos acima.

Bergstein (2013, p. 209) defende que a obtenção do consentimento do paciente na forma escrita seja obrigatória em algumas situações especiais, vejamos: $1^{\circ}$ ) quando o procedimento envolver a retirada de consciência do paciente por anestesia; $2^{\circ}$ ) quando for invasivo (mesmo os minimamente invasivos, como é o caso das endoscopias); 3º quando há risco considerável para a saúde do paciente; e $4^{\circ}$ ) quando se tratar de pesquisas biomédicas realizadas com seres humanos.

Esses critérios oferecem um bom parâmetro e são, inclusive, muito parecidos com os que estão fixados nas leis estrangeiras da Espanha e da Argentina sobre o direito de autodeterminação do paciente.

O critério sugerido acima, entretanto, deveria ser incorporado a uma normativa orientadora para não ficar restrito apenas ao campo da sugestão doutrinária, garantindo, assim, a necessária segurança na implementação do direito de autodeterminação.

15 O que de fato ocorre naquele país, como bem atestam Bernat e Peterson (2006, p. 87, tradução nossa): "alguns cirurgiões veem o consentimento como um requisito jurídico [apenas] e, com frequência, delegam essa atividade a um médico residente." 
Em acréscimo à sugestão do autor, é preciso considerar o perigo da burocratização e do distanciamento da prática ética necessária à formação da vontade autônoma, pelo potencial perigo de burocratização na assinatura de formulários. Para isso, compreendemos que os TCI's devem seguir alguns pressupostos éticos a fim de que possam ser considerados eficazes e adequados.

O primeiro pressuposto seria relativo ao tempo de sua proposição. $\mathrm{O}$ esclarecimento e a autorização devem ser anteriores à intervenção porque, obviamente, o paciente somente pode autorizar certo procedimento de forma eficaz se todos os elementos necessários para a formação de sua convicção forem apresentados e esclarecidos antes do procedimento médico. Um TCI assinado após a intervenção ou na iminência de entrar em um centro cirúrgico, por exemplo, não deveria ser considerado válido.

Há, ainda, que se considerar o local em que é assinado o TCI, contudo acontece que, muitas vezes, a realização de um TCI é considerada uma etapa menor pelos médicos. Essa tarefa acaba sendo desempenhada por terceiros, por exemplo, atendentes administrativos de hospitais e clínicas, que, em geral, "colhem a assinatura do paciente" em meio ao preenchimento de outros documentos necessários para a prática do procedimento médico, como guias de internação do paciente, pedidos médicos etc. A estandardização dos TCl's e o ato de delegar essa função a terceiros não é um problema apenas no Brasil. Diante disso, Dias Pereira expressa essa mesma preocupação na prática clínica portuguesa:

A assinatura do formulário pode ser, por si só, um momento de reflexão e de autoconscientização dos direitos da pessoa. Poderá mesmo ser o espaço privilegiado de diálogo entre médico e paciente relativamente aos riscos e as alternativas da intervenção a realizar. O que não se pode admitir que se use este expediente como arma de arremesso jurídico que se obtém no "guichet" de um departamento administrativo, como acontece em tantos dos nossos hospitais (PEREIRA, 2004, p. 540).

Os Termos devem prever igualmente as intercorrências previsiveis e as consequências iatrogênicas habituais do procedimento a que o paciente se submeterá, e, como regra, estas devem ser explicadas ao paciente para a obtenção de sua concordância. Esse tem sido um problema recorrente nos processos judiciais analisados.

Por último, é necessário, do ponto de vista ético, que o paciente seja esclarecido sobre a natureza e a função do TCI na relação médica. È importante que seja entendido como o culminar do direito que assiste ao paciente sobre o curso da intervenção que deseja realizar, evitando que seja entregue junto a guias de internação hospitalar ou que seja demandada a assinatura do paciente sem o prévio esclarecimento sobre a natureza do documento que está assinando.

A relação entre o consentimento do paciente e sua comprovação jurídica é uma das grandes dificuldades na prática judicial, e nem mesmo a doutrina apresenta uma saída satisfatória para a solução dessa controvérsia.

Outra grande dificuldade consiste na utilização do conceito fora do seu contexto de origem. 
O consentimento informado tem como finalidade garantir o processo de decisão autônoma do paciente na relação médica. É fato notório que a autonomia individual é um importante princípio jurídico que rege os contratos, mas, quando se fala em "consentimento informado", a autonomia do paciente tem um significado especial, porque representa a superação da relação médico-paciente centrada no paradigma hipocrático. Isso significa que o respeito à autonomia exigido no consentimento não possui apenas uma dimensão jurídico-contratual (formal), mas uma dimensão ética que não pode estar apartada da primeira. No entanto, verificamos que não só a expressão, mas também o próprio conceito de consentimento informado tem sido aplicado, por exemplo, em relações bancárias, pelo simples fato de possuir elementos supostamente comuns: como a vulnerabilidade de uma das partes e a omissão de informações.

É possível verificar o uso indevido do conceito do consentimento informado em um caso que versava sobre um cancelamento unilateral de conta-corrente:

O consentimento é um processo e não uma forma, razão pela qual tem que ser obtido ao final de um indispensável diálogo, através do qual as partes trocam informações e se interrogam reciprocamente, culminando com a formalização da aderência aos termos e condições pelo fornecedor propostas. $O$ consentimento informado, ou consentimento esclarecido, não pode ser visto, pois, como uma simples formalidade. É, sem maiores digressões, o resultado de um diálogo em que fornecedor e consumidor que, imbuídos da mais estrita boa-fé, buscam esclarecer dúvidas, e que não se encerra com o simples lançamento da assinatura do aderente no espaço pelo fornecedor no contrato reservado (BRASIL, 2009b, p. 7).

Encontramos ao todo 15 (quinze) decisões que utilizam a expressão e o conceito de "consentimento informado" de forma equivocada: como no emprego do conceito em relação entabulada entre o consumidor e a seguradora de saúde, sem que houvesse uma relação médico-paciente sob questão, mas um mero defeito de serviço, a saber: a não cobertura de UTI neonatal (BRASIL, 2011). O conceito também foi utilizado em: negativa de pagamento de seguradora de saúde para internação em clínica de dependência química (BRASIL, 2014a), atraso de entrega de imóvel por incorporadora (BRASIL, 2015a), compra de veículo automotor sem advertências necessárias sobre as alterações de marca e modelo (BRASIL, 2015b), entre outras.

Essa utilização indevida do conceito se deve aparentemente ao fato de que parte dos intérpretes compreende que o consentimento informado seria uma espécie de "dever de informação", independentemente da qualificação dos sujeitos que compõem a relação jurídica. Assim, em uma dessas decisões que trata de uma cobrança indevida por parte de um plano de saúde, o relator do caso sustenta que "[...] não houve o consentimento informado por parte dos Réus ao Autor acerca das despesas 'não financiadas', de modo que se mostra abusiva essa cobrança, estando, portanto, correta a decisão do Juízo singular que reconheceu a nulidade da dívida, ante a violação do dever de informação.” (BRASIL, 2016, p. 5).

O consentimento informado não se esgota apenas em informar os riscos ao paciente. Como esclarece Beauchamp e Childress (2011), a ênfase exagerada de acentuar a dimensão 
da revelação da informação acaba por desnaturar o entendimento mais adequado da noção.

Definitivamente, essas interpretações do conceito para relações jurídicas consumeristas em geral atrapalham o processo de consolidação do direito de autodeterminação no âmbito clínico.

Contudo, como já se sustentou, há, felizmente, mais aspectos positivos que negativos nas análises das decisões judiciais. Os aspectos a serem celebrados não se esgotam apenas no âmbito das condenações pela violação ao consentimento do paciente, mas vão além.

$\mathrm{Na}$ análise das decisões, procurou-se também traçar uma correlação entre o erro da técnica médica, vulgarmente chamado de "erro médico", e a violação ao consentimento informado. Para verificar mais detidamente essa correlação, os dados dos laudos periciais, quando presentes nos recursos judiciais, foram cruzados com a prática do consentimento informado a partir dos seguintes parâmetros:

Tabela 2 - relações entre o CI e a perícia técnica

\begin{tabular}{l|l|l}
\hline Relação entre o CI e a Técnica Médica Empregada & TOTAIS & $\%$ \\
\hline 1. Dispensada prova pericial; não se aplica; não menciona ou é inconclusiva. & 18 & $39,13 \%$ \\
\hline 2. Mérito versa apenas sobre o CI. & 1 & $2,17 \%$ \\
\hline 3. Procedimento médico inadequado e ausência ou falha no CI. & 5 & $10,87 \%$ \\
\hline 4. Adequação do procedimento médico, mas com ausência ou falha no CI. & 19 & $41,30 \%$ \\
\hline 5. Não há erro médico, nem falha no CI. & 3 & $6,52 \%$ \\
\hline & 46 & $100,00 \%$ \\
\hline
\end{tabular}

No item 1 da tabela 2, os casos, apesar de versarem sobre o consentimento informado e o erro da técnica no procedimento médico, dispensaram a prova pericial. Na maioria das vezes, isso ocorreu porque o erro médico era flagrante, a ponto de se tornar desnecessário o recurso a esse tipo de prova, mas também representa os casos em que a prova pericial foi incapaz de apresentar um resultado conclusivo a partir dos documentos médicos e dos elementos fáticos apresentados no caso concreto.

No item 2, a demanda processual tratava, em seu mérito, apenas sobre o consentimento informado, motivo pelo qual a perícia foi considerada desnecessária.

O item 3 retrata a realidade dos casos em que houve, concomitantemente, um erro médico de técnica e uma falha no consentimento informado.

O item 5 representa os casos em que houve perícia acerca da técnica médica, porém nem esta foi considerada inadequada, nem o consentimento informado foi desrespeitado.

Já o item 4 merece destaque, pois representa a visão de que o direito de autodeterminação pode sofrer violação mesmo quando o profissional atua adequadamente do ponto de vista técnico, isto é, a prática do consentimento informado aparece aqui como uma noção autônoma em relação ao erro médico. Essa foi a compreensão em mais de 41,30\% dos casos analisados. 
Esse dado impõe uma nova consideração para a relação médico-paciente, na medida em que amplia os deveres e a noção jurídica de culpa do profissional, que passa a responder não apenas pela técnica médica realizada dentro de parâmetros considerados adequados, como também pelos deveres relativos à ética que integram a prática do consentimento informado.

Além disso, o agir médico ganha nova dimensão, pois deixa de guiar-se apenas pelos ditames da ciência médica, a qual exige que o profissional seja diligente nas regras de sua arte (leges artis), para que atue respeitando e até potencializando as decisões autônomas de seus pacientes. É nessa correlação entre ética e ciência que a noção jurídica de culpa profissional se torna mais abrangente, pois pode ocorrer violação ao dever profissional por erro de técnica ou por violação ao direito de autodeterminação. A culpa do profissional abrange ambas as perspectivas, as quais passam a ser compreendidas como independentes, porém conexas.

Uma decisão judicial datada de 2006 (BRASIL, 2006), por exemplo, traz um caso em que o paciente foi submetido a uma prostatectomia radical e apresentou um quadro pós-cirúrgico de incontinência urinária. Foi proposto um procedimento cirúrgico de reconstrução artificial do esfíncter, para o qual necessitou de doação de tecido de um parente compatível. $\mathrm{O}$ procedimento foi realizado seguindo a técnica adequada, mas sem sucesso. Sublinha-se aqui que o cirurgião não estava adstrito a alcançar o resultado satisfatório, mas, mesmo assim, foi condenado por não ter advertido o paciente sobre a possibilidade de insucesso.

Qual a base jurídica para atribuir a responsabilidade pela violação ao consentimento informado, uma vez que não há no ordenamento pátrio uma regra específica?

O direito de autodeterminação tem sua base fundamental nos direitos da personalidade. Explica Cupis (2008, p. 23 e ss.) que os direitos de personalidade são todos aqueles destinados a dar conteúdo à personalidade, constituindo um mínimo necessário e imprescindível para a vida em sociedade, sem eles a personalidade não poderia ser plenamente realizada e ficaria privada de valor concreto, pois os demais direitos perderiam interesse de proteção.

Os direitos de personalidade são, portanto, essenciais para a prática dos demais direitos que compõem o patrimônio jurídico de uma pessoa e guardam um vínculo direto com a proteção constitucional à dignidade da pessoa humana, que é o princípio maior de toda ordem constitucional.

A tutela especial reservada pelo ordenamento jurídico aos direitos da personalidade está diretamente relacionada à proteção do consentimento informado, como explica Cupis (2008, p. 31): "A vida, a integridade física, a liberdade, e outros, constituem aquilo que nós somos. Ora, não se vê porque razão o legislador deveria limitar-se a proteger a categoria do ter, tanto mais que esta última abraça [...] os bens mais preciosos relacionados à pessoa.”

Os direitos da personalidade são tão suscetíveis de sofrerem dano como os direitos de natureza patrimonial e, embora eles não sejam passíveis de avaliação econômica, sua violação enseja uma resposta jurídica para compensar o dano causado, uma vez que são considerados direitos essenciais e base para o exercício dos demais direitos.

O consentimento informado agrega, em sua base ético-jurídica, esses valores fundamentais 
para o exercício da personalidade, razão por que sua violação constitui um dano autônomo e independente em relação à técnica médica empregada.

\section{CONCLUSÕES}

A análise das decisões do TJRJ sobre o consentimento informado revela que o conceito ainda não foi totalmente compreendido pelo Poder Judiciário, porque muitas decisões o utilizam para situações em que não há uma relação entre médico e paciente.

Não obstante a existência dessas decisões que utilizam equivocadamente o instituto, é possível afirmar que é sensível a preocupação do Poder Judiciário Fluminense com o direito de autodeterminação do paciente. $\mathrm{O}$ que é algo positivo, para um conceito jurídico recente que ainda está em construção.

Dificuldades maiores ainda persistem para encontrar um caminho satisfatório entre os aspectos formais, que revestem a prática do consentimento informado, e sua dimensão dialógica e ética, que constitui sua essência. A ênfase demasiada na formalização do procedimento é potencialmente nociva à prática real do consentimento, mormente quando essa prática é desenvolvida sem um diálogo efetivo entre médico e paciente. Como consequência, as práticas habituais de padronização de seu conteúdo, sem que se considere o quadro clínico concreto do paciente individualizado, ou que estabeleçam um procedimento burocrático fora da relação médico-paciente, não podem ser consideradas nem válidas do ponto de vista jurídico e nem legítimas do ponto de vista moral.

Os TCI's devem representar o culminar de um processo comunicativo que, de fato, traduza o consentimento autônomo do paciente. A observação dessa regra é fundamental para que o direito de autodeterminação do paciente no âmbito clínico possa ser efetivo e eficaz, e não uma fórmula demagógica sem qualquer lastro moral.

A análise das decisões revelou, por fim, que o consentimento informado, em sua dimensão jurídica, não é apenas uma obrigação acessória na prática médica, mas uma obrigação autônoma. Essa evolução do pensamento jurídico descortina nova compreensão para a relação médico-paciente, a qual passa a integrar de forma indissociável a técnica médica aos deveres éticos, fazendo do direito de autodeterminação uma expressão dos direitos da personalidade.

O respeito ao direito de autodeterminação dos pacientes no âmbito clínico apresenta-se como uma realidade concreta na seara do direito. Ainda há muito a ser trilhado para a sua consolidação plena, mas as decisões judiciais desenham um horizonte favorável para o futuro.

\section{REFERÊNCIAS}

ARGENTINA. Lei 26.529, de 21 de outubro de 2009. Derechos del Paciente en su Relación con los Profesionales e Instituciones de la Salud. Disponível em: http://www.uba.ar/ archivos_secyt/image/Ley\%2026529.pdf. Acesso em: 15 jan. de 2015.

ARGENTINA. Lei 27.742, de 09 de maio de 2012. Modifica a Lei 26.529/09. 
BEAUCHAMP, Tom L. Autonomy and consent. In: MILLER, Franklin G.; WERTHEIMER, Alan. The ethics of consent: theory and practice. Nova Iorque: Oxford, 2010. p. $55-78$.

BEAUCHAMP, Tom L.; CHILDRESS, James F. Princípios de ética biomédica. 2. ed. São Paulo: Loyola, 2011.

BEAUCHAMP, Tom L.; FADEN, Ruth. Informed consent. In: STEPHEN, Gerrard Post (ed.). Encyclopedia of bioethics. Nova Iorque: Thomsom Gale, 1995. v. 3.

BEAUCHAMP, Tom L.; FADEN, Ruth. A history and theory of informed consent. Nova Iorque: Oxford, 1986.

BERG, Jessica W. et al. Informed consent: legal theory and clinical practice. 2. ed. Nova Iorque: Oxford, 2001.

BERGSTEIN, Gilberto. A informação na relação médico-paciente. São Paulo: Saraiva, 2013.

BERNAT, James L.; PETERSON, Lynn M. Patient-centered informed consent in surgical practice. Archives of Surgery, v. 141, n. 1, p. 86-92, 2006.

BRASIL. Código civil brasileiro. Lei no 10.406, de 10 janeiro de 2002. São Paulo: Saraiva, 2014b.

BRASIL. Lei n o 10.406, de 10 de janeiro de 2002. Institui o Código Civil. Brasília, DF: Presidência da República, 2002. Disponível em: http://www.planalto.gov.br/ccivil_03/ leis/2002/110406.htm. Acesso em: 15 jan. de 2015.

BRASIL. Código de defesa do consumidor. Lei no 8.078, de 11 de setembro de 1990. Brasília, DF: Presidência da República, 1990. Disponível em: http://www.planalto.gov.br/ ccivil/leis/18078.htm. Acesso em: jan. de 2015.

BRASIL. Código de Ética Médica: Resolução CFM no 2.217, de 27 de setembro de 2018, modifiada pelas Resoluções CFM n².222/2018 e 2.226/2019. Conselho Federal de Medicina. Brasília:

Conselho Federal de Medicina, 2019.

BRASIL. [Constituição (1988)]. Constituição da República Federativa do Brasil de 1988. Brasília, DF: Presidência da República, 1988. Disponível em: http://www.planalto. gov.br/ccivil_03/Constituicao/CConstituiçao.htm. Acesso em: 15 jan. 2015.

BRASIL. Constituição (1988). Constituição da República Federativa do Brasil de 1988. São Paulo: Saraiva, 2013b. 
BRASIL. Tribunal de Justiça do Estado do Rio de Janeiro. Apelação Cível $\mathbf{n}^{\mathbf{o}}$ 2003.001.03239. 9a Câmara Cível. Relator Desembargador Laerson Mauro. Rio de Janeiro, 18 de março de 2003.

BRASIL. Tribunal de Justiça do Estado do Rio de Janeiro. Apelação Cível no 0031029 61.2003.8.19.0001. 9a Câmara Cível. Relator Desembargador Roberto de Abreu Silva. Rio de Janeiro, 17 de outubro de 2006.

BRASIL. Tribunal de Justiça do Estado do Rio de Janeiro. Apelação Cível n ${ }^{\mathbf{o}}$ 2006.001.67409. Relator Des. Ricardo Rodrigues Cardoso. Rio de Janeiro, 13 de fevereiro de 2007, p. 3.

BRASIL. Tribunal de Justiça do Estado do Rio de Janeiro. Apelação Cível no 2008.001.28159. 9a Câmara Cível. Relator Desembargador Roberto de Abreu e Silva. Rio de Janeiro, 30 de setembro de 2008.

BRASIL. Tribunal de Justiça do Estado do Rio de Janeiro. Apelação Cível no 0124722 65.2004.8.19.0001 (2008.001.59764). 7ª Câmara Cível. Relator Desembargador Ricardo Couto de Castro. Rio de Janeiro, 4 de fevereiro de 2009a, p. 4.

BRASIL. Tribunal de Justiça do Estado do Rio de Janeiro. Apelação Cível n. 007240780.2006.8.19.0004. Relator Desembargador Maldonado de Carvalho. Rio de Janeiro, 25 de junho de 2009b, p. 7.

BRASIL. Tribunal de Justiça do Estado do Rio de Janeiro. Apelação Cível n. 0011159 80.2010.8.19.0002. 19a Câmara Cível. Relator Desembargador Paulo Sérgio Prestes. Rio de Janeiro, 09 de agosto de 2011.

BRASIL. Tribunal de Justiça do Estado do Rio de Janeiro. Apelação Cível no $0468415-$ 45.2012.8.19.0001. 7a Câmara Cível. Relator Desembargador Marcos Alcino de A. Torres. Rio de Janeiro, 20 de dezembro de 2013a.

BRASIL. Tribunal de Justiça do Estado do Rio de Janeiro. Apelação Cível n. 000416450.2012.8.19.0206. Relatora Des. Maria Luiza de Freitas Carvalho. 23a Câmara Cível. Rio de Janeiro, 16 de junho de 2014a.

BRASIL. Tribunal de Justiça do Estado do Rio de Janeiro. Apelação Cível n. 002803685.2012.8.19.0209. Relator Des. Antonio Carlos dos S. Bitencourt. 27ª Câmara Cível. Rio de Janeiro, 12 de março de 2015a.

BRASIL. Tribunal de Justiça do Estado do Rio de Janeiro. Apelação Cível n. 000537833.2009.8.19.0028. Relator Des. Juarez Fernandes Folhes. 26ª Câmara Cível. Rio de Janeiro, 16 de janeiro de $2015 \mathrm{~b}$.

BRASIL. Tribunal de Justiça do Estado do Rio de Janeiro. Apelação Cível n. 0009275- 
21.2012.8.19.0204. Relatora Des. Maria Regina F. Nova Alves. Rio de Janeiro, 16 de agosto de 2016, p. 5.

CUPIS, Adriano de. Os direitos da personalidade. São Paulo: Quorum, 2008.

D ' AGINCOURT-CANNING, Lori; JOHNSTON, Carolyn. Disclousure. In: SINGER, Peter A.; VIENS, A. M. (ed.). The Cambridge textbook of bioethics. Nova Iorque: Cambridge University Press, 2008.

DYKEMAN, Mary Jane; DEWHIRST, Kate. Voluntariness. In: SINGER, Peter A.; VIENS, A. M. (ed.). The Cambridge textbook of bioethics. Nova Iorque: Cambridge University Press, 2008.

ESPANHA. Lei 41, de 14 de novembro de 2002. Básica reguladora de la autonomía del paciente y de derechos y obligaciones en materia de información y documentación clínica. 2002. Disponível em: https://www.boe.es/buscar/act.php?id=BOE-A-2002-22188. Acesso: em 12 jul. 2019.

FRISCH, Wolfgang. Consentimento e consentimento presumido nas intervenções médico-cirúrgicas. Tradução de Costa Andrade. Revista Portuguesa de Ciência Criminal, Coimbra, v. 14, n. 1/2, p. 67-115, 2004.

HARRIS, John. The valeu of life: an introduction to Medical Ethics. London and Nova Iorque: Routledge, 2001.

HIPPOCRATES. Ancient medicine: air, water, places; Epidemics, The oath, Precepts, Nutriment. Tradução para o inglês por W. H. S. Jones. Londres: William Heinemann, 1957. v. 1.

KATZ, Jay. The silent world of doctor and patient. Maryland: John Hopkins University Press, 2002.

LOPES JUNIOR, Dalmir. Consentimento informado na relação médico-paciente. Belo Horizonte: D’Plácido, 2018.

PEREIRA, André Gonçalo Dias. O consentimento para intervenções médicas prestado em formulários: uma proposta para o seu controlo jurídico. Boletim da Faculdade de Direito, Coimbra, v. 76, p. 433-471, 2000.

PEREIRA, André Gonçalo Dias. O consentimento informado na relação médico-paciente: estudos de direito civil. Coimbra: Coimbra Editora, 2004.

PITHAN, Lívia Haygert. O consentimento informado no poder judiciário brasileiro. Revista da AMRIGS, v. 56, n. 1, p. 87-92, jan./mar. 2012.

SABADELL, Ana Lúcia. Manual de sociologia jurídica: introdução a uma leitura externa do direito. São Paulo: Revista dos Tribunais, 2005. 
WEAR, Stephen. Informed consent. In: KHUSHF, George (ed.). Handbook of bioethics: taking stock of the field from a philosophical perspective. Nova Iorque: Kluwe Academics Publishers, 2004.

WILLIAMS, John R. Consent. In: SINGER, Peter A.; VIENS, A. M. (ed.). The Cambridge textbook of bioethics. Nova Iorque: Cambridge University Press, 2008. 